\title{
Lubricant film thickness and friction force measurements in a laser surface textured reciprocating line contact simulating the piston ring - liner pairing
}

\author{
Sorin-Cristian Vlădescu ${ }^{\mathrm{a}}$, Simon Medina ${ }^{\mathrm{a}}$, Andrew V. Olver ${ }^{\mathrm{a}}$, Ian G. Pegg ${ }^{\mathrm{b}}$, Tom Reddyhoff ${ }^{\mathrm{a},{ }^{*}}$ \\ ${ }^{a}$ Tribology Group, Department of Mechanical Engineering, Imperial College London, South Kensington, Exhibition \\ Road, SW7 2AZ, London, United Kingdom \\ ${ }^{\mathrm{b}}$ Ford Motor Company, Dunton, Essex, United Kingdom \\ * Corresponding author. Tel.: +44 (0) 2075943840 e-mail address: t.reddyhoff@imperial.ac.uk
}

\begin{abstract}
Applying surface texture to piston liners may provide an effective means of controlling friction and hence improving engine efficiency. However, little is understood about the mechanisms by which pockets affect friction, primarily because of a lack of reliable experimental measurements. To address this, the influence of surface texture on film thickness and friction force was measured simultaneously in a convergent-divergent bearing, under conditions that closely replicate an automotive piston ring-liner conjunction. Film thicknesses were measured using a modified version of the ultra-thin film optical interferometry approach, enabling film thicknesses <50 nanometres to be measured under transient, mixed lubrication conditions. This involved using the out-of-contact curvature of the specimens in place of a spacer layer and analysing multiple interference fringes to avoid fringe ambiguity. Tests were performed on both a textured sample (with features oriented normal to the direction of sliding) and a non-textured reference sample, while angular velocity, applied normal load and lubricant temperature were controlled in order to study the effect of varying lubrication regime (as typically occurs in service). Results showed that the presence of surface pockets consistently enhances fluid film thickness in the mixed lubrication regime by approximately $20 \mathrm{~nm}$. Although this is only a modest increase, the effect on friction is pronounced (up to $41 \%$ under these conditions), due to the strong dependence of friction on film thickness in the mixed regime. Conversely, in the full film regime, texture caused a reduction in film thickness and hence increased friction force, compared with the non-textured reference. Both textured and non-textured friction values show nearly identical dependence on film thickness, (showing that, under these conditions, texture-induced friction reduction results entirely from the change in film thickness). These results are important in providing film thickness data to validate piston-ring lubrication models and also in helping to understand the effect of surface roughness on texture performance.
\end{abstract}

Keywords: Surface texture, Surface patterning, Piston rings, Optical interferometry, Thin film lubrication. 


\section{Background}

\subsection{Surface Texture}

It has long been known that surface texturing can improve tribological performance in a wide range of applications. Examples from nature include fish that use surface texturing to reduce hydrodynamic drag and plant leaves that use the "lotus leaf" effect to achieve selfcleaning [1-3]. These natural occurrences have inspired many attempts to artificially texture the surfaces of components in engineering applications.

Various beneficial effects of surface texture on tribological performance have been proposed in the academic literature. These include $i$ ) sliding fiction force reduction [4-15] due to increased load support, ii) wear reduction under dry and boundary lubricating conditions due to "debris trapping" [9,16-20] and iii) starvation prevention due to the provision of secondary lubricant reservoirs [9,16,21-24]. In addition, a recent study by Greiner et al. [25] suggested that surface texture can reduce static friction by a factor of two, provided an optimum dimple diameter is selected. Because of these potential advantages, surface texture is currently being applied to various components in modern IC (internal combustion) engines [26]; Gehring $\mathrm{GmbH}$ being the first company to offer LST commercially.

Typically, surface features are typically created in engineering applications through laser texturing (also known as LT, LST, or laser honing). However, due to the high manufacturing costs and speed limitations of LST, alternative texturing methods for tribological surfaces are becoming increasingly prevalent. A recent study by Costa and Hutchings [27] investigates and classifies existing texturing techniques and explores a variety of innovative methods which may be employed in the future.

Research into the friction reducing effects of surface texture started with the introduction of the concept of "micro-irregularities" by Hamilton and Allen in 1966 [28,29]. They pointed out that by adding "asperities and depressions" to one face of a parallel rotaryshaft face seal, the load support capabilities of the seal could be improved. Various subsequent analytical and experimental studies into the effect and performance of textured bearings have been carried out, with an increasing frequency in the last decade. The majority of these studies investigated the effects of patterned surfaces in hydrodynamic, full film conditions [30-35], whilst a few tested the effects of geometric patterns on elastohydrodynamic lubrication [36,37] or boundary and/or mixed lubrication [20,38-41]. From these studies, it seems increasingly clear that texture is most effective in the mixed and boundary regime, where it can lead to friction reductions of more than $50 \%$ (for example see [4]) - a finding that has important implications for reducing fuel consumption in automotive contact, such as the piston-liner conjunction. However, the mechanisms through which laser textured patterns prove beneficial remains unclear. This is in part due to the fact that the vast majority of research focused on sliding friction force, with few oil film thickness measurements being attempted

Only a limited number of texture studies have used test rigs to simultaneously measure friction and oil film thickness response. Of particular significance is the work carried 
out by Costa and Hutchings [30] who developed a reciprocating test rig to investigate friction force and lubricant film thickness in a full-film hydrodynamic contact. In this case, they employed a capacitance technique to study the effect of geometrical characteristics of laser surface texture on oil film thickness. They also investigated various textured patterns and concluded that chevron patterns where the most effective in increasing the hydrodynamic lubricant film thickness, while grooves parallel to the direction of sliding proved least effective. Apart from that study, simultaneous measurement of film thickness and frictional response of textured interfaces in boundary and mixed lubrication regimes has so far largely escaped attention, possibly due to the difficulty in measuring film thickness in a sliding contact under such thin film conditions.

\subsection{Film thickness measuring for textured contacts}

Here, we briefly review techniques used to measure film thickness in textured contacts under different lubrication regimes.

- Optical interferometry has been employed as a tool to measure lubricant film thickness since the 1960s [42]. In 1996, Cann et al. developed the Spacer Layer Imaging Method (SLIM) [43], which, combined with high-performance video cameras, allowed automatic colorimetric imaging of interference images and film thickness mapping of mixed and boundary lubricated contacts below $150 \mathrm{~nm}$. In 2001, Spikes and Cann employed SLIM to study asperity film formation for the first time in detail [44]. In that study, film thickness maps were obtained for ball specimens with transverse and longitudinal ridges as well as for arrays of small bumps. The optical interferometry technique was later applied to oil film thickness mapping of microtextured bearing surfaces, typically using ball-on-disc tribometers. Mourier et al. [37] analysed the effects on lubricant film thickness of isolated micro-cavities passing through an elasto-hydrodynamic (EHD) point contact. This showed that, under pure rolling conditions, there are no significant changes in film thickness as the dimple passes through contact. However, under rolling-sliding conditions, two different effects of the micro-cavity passing through contact were observed: $i)$ deep cavities $(7 \mu \mathrm{m})$ tend to decrease the oil layer locally as the pocket enters the contact, while $i i)$ shallow dimples $(1.3 \mu \mathrm{m})$ exhibit the opposite effect, increasing the lubricant film thickness when the bearing operates under EHD regime.

In a similar study employing pocketed steel balls on glass discs, Krupka and Hartl [45] also analysed the effect of texture depth on thin EHD lubrication films. Optical interferograms and cross-section profiles of the film thickness were plotted for various textured surfaces with micro-dents depths varying between $560 \mathrm{~nm}$ and $1900 \mathrm{~nm}$. Similar to Mourier's observations, the authors concluded that deep micro-dents lead to a reduction in oil film thickness downstream the leading edge. Furthermore, a slightly reduced pocket depth again led to a reduction in measured friction. The same group also used a thin film colorimetric interferometry technique to observe the behaviour of shallow 
micro-dents under mixed lubrication conditions [24]. Here, results showed a significant local increase in oil film thickness as shallow micro-dents (depths between 200 and $300 \mathrm{~nm}$ ) passed through mixed lubricated contacts.

Another study involving oil film thickness measurement by optical interferometry worth mentioning is the work by Kaneta et al. [46]. They built a reciprocating test apparatus which enabled simultaneous measurements of friction force and lubricant film thickness in a line contact. Although the main purpose of the study was to observe the influence of cross sectional shape and stroke length of the rubber seal upon friction force and film thickness, a surface defect in the shape of a dent was also investigated. In this case, a local increase in film thickness was observed downstream from the dent.

These studies show that optical interferometry is a powerful technique to measure film thickness under mixed and boundary conditions. However, under the reciprocating conditions present in an automotive piston-liner type contact, the reliance on a semi-reflective coating on that transparent specimen is problematic due to issues of wear.

- Laser Induced Fluorescence (LIF) is a technique commonly used to determine lubricant film thickness in a tribological contact. Based on the photo-excitation of a fluorescent dye, this technique proves difficult to use in conjunction with textured surfaces, as additional light from the deeper pockets distorts film thickness measurements. However, LIF has proved reliable when measuring oil film thicknesses in non-textured lubricated contacts (e.g. $[47,48]$ ), and imaging the cavitation pattern encountered at the outlet of tribological contacts [4]. LIF has been applied to automotive contacts by Dearlove and Cheng [49] who simultaneously measured mid-stroke lubricant film thickness and friction force in a single piston ring-floating liner nontextured assembly. Although the frictional behaviour was found consistent with Stribeck diagrams while running in both hydrodynamic and mixed regimes, the authors reported difficulties in calibrating the LIF signal.

- Ultrasonic Sensing has been developed over the last decade as a tool to measure film thickness in tribological contacts (e.g.[50,51]) and has recently been applied in IC engine cylinder liner applications by mounting elements to the cylinder wall [52,53]. Although this approach has the advantage of being non-invasive (it can be used on actual components without requiring a transparent window), it has disadvantages in terms of spatial resolution (which is typically larger than piston-liner contact area) and minimum measurable film thickness of around $50 \mathrm{~nm}$ (despite showing potential to distinguish asperity and liquid stiffness under mixed lubrication conditions [54]).

In conclusion, very few studies of reciprocating micro-textured bearings employ film thickness measurements, mainly due to the difficulty in performing such measurements under mixed and boundary conditions. As a result, there remain uncertainties regarding the mechanisms by which surface pockets affect friction. Optical interferometry is an effective 
technique for measuring film thickness under boundary conditions; however its reliance on a semi-reflective coating usually limits its application to rolling conditions in order to preserve the coating. In order to overcome this limitation and study the effect of surface texture on film thickness in a piston-liner type contact, this study uses a modified version of the standard optical interferometry technique and a test rig specifically designed to replicate the contact conditions in a piston-liner conjunction.

\section{Description of the reciprocating apparatus}

This study uses a custom built reciprocating test apparatus that enables simultaneous measurement of friction, film thickness and cavitation behaviour of textured and non-textured surfaces. Designed with the main purpose of closely replicating an IC engine's tribological contact between the piston ring and cylinder liner, the main structural features of this test apparatus are shown in Fig. 1 (the reciprocating pad is labelled A and the stationary ring specimen is labelled $\mathrm{B}$ ).

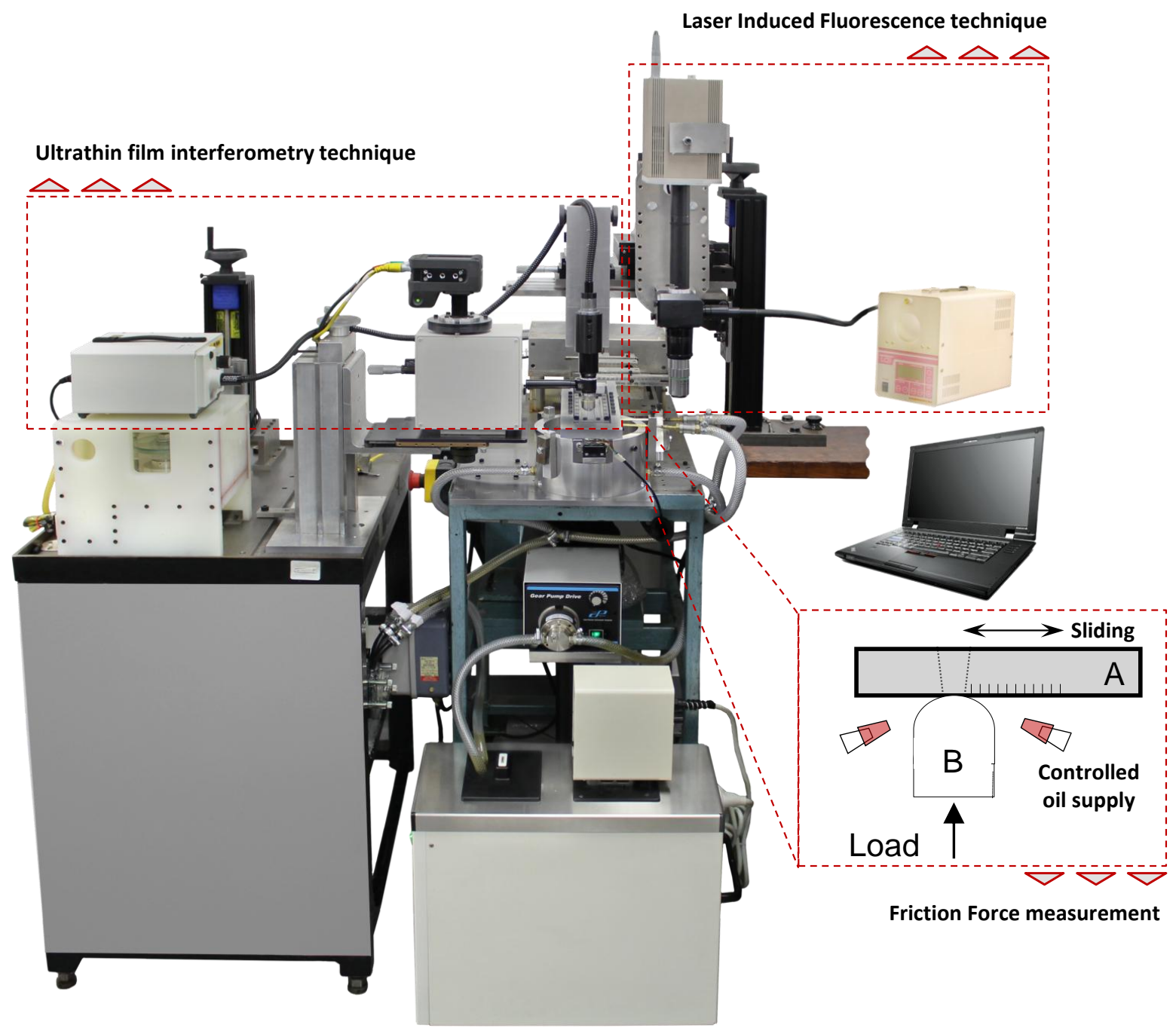

Figure 1 - Original layout of the reciprocating test rig 
The reciprocating motion of the fused silica pad along two linear bearings is ensured by an electric motor which drives an adjustable stroke mechanism. The latter allows the piston-liner motion to be accurately controlled in order to replicate automotive conditions. The stroke length selected for this study is $28.6 \mathrm{~mm}$. Two centrifugal governors ensure the continuous and smooth sliding movement of the silica plate is maintained at both ends of the stroke. Due to the governor inertia, the reciprocating motion of the silica plate holder is forced to continue after each of the dead centres is reached. The reciprocating velocity and angular position of the contact is measured by means of a rotary position encoder, fixed to the bottom of the cam mechanisms' shaft.

Friction force is captured using a high sensitivity load cell, connected by a rod to an adjustable mechanism that holds the lower specimen. The holding mechanism ensures near perfect alignment of the curved steel pad against the counterpart fused silica pad that represents the cylinder liner. The operating normal load can be varied between $10 \mathrm{~N}$ and 120 $\mathrm{N}$ using multiple dead weights connected to the silica pad specimen holder.

Two nozzles attached to the oil bath provide a supply of lubricant to both sides of the contact region. A sufficient quantity of fully formulated SAE 40 oil thus reaches the contact, preventing inlet starvation. Preliminary tests demonstrated that oil temperature is the most important operating parameter due to its effect on lubricant viscosity. As even a slight variation in temperature can radically alter measured friction values, a precise oil supply system was designed. This involved an immersion circulator, to regulate lubricant temperature within a range of $+10^{\circ} \mathrm{C}$ to $+150^{\circ} \mathrm{C}$ and with a stability of $0.2^{\circ} \mathrm{C}$, and a gear pump and peristaltic pump to convey the lubricant to and from the contact. This precise temperature control allows textured and non-textured bearing configurations to be assessed under boundary, mixed and full film lubrication regimes.

Film thickness and frictional response for individual textured and non-textured specimens are measured at every location along the stroke of the silica pad using a 9 bit triggering system with a precision equal to 0.7 degrees of crankshaft revolution.

\section{Determination of film thickness using a multiple wavelength, out of contact, ultrathin- film interferometry approach}

A key requirement in this study is the measurement of oil film thickness in addition to friction force, in both the full film and the mixed lubrication regimes. To achieve this, a variation of the optical ultrathin-film interferometry technique was devised allowing sub 50 $\mathrm{nm}$ film thickness to be monitored, without using a silicon spacer layer. Optical interferometry was chosen, due to its ability to accurately quantify nanometre scale film thicknesses. This technique typically involves reflecting light off the top and bottom of an oil film and calculating its thickness based on the wavelength, at which constructive or destructive interference occurs, and the fringe order (i.e. the number of complete wavelengths between the two rays). 
The method to achieve this is outlined schematically in Figure 2 and involves positioning an optical microscope above the stationary ring specimen and focussing through

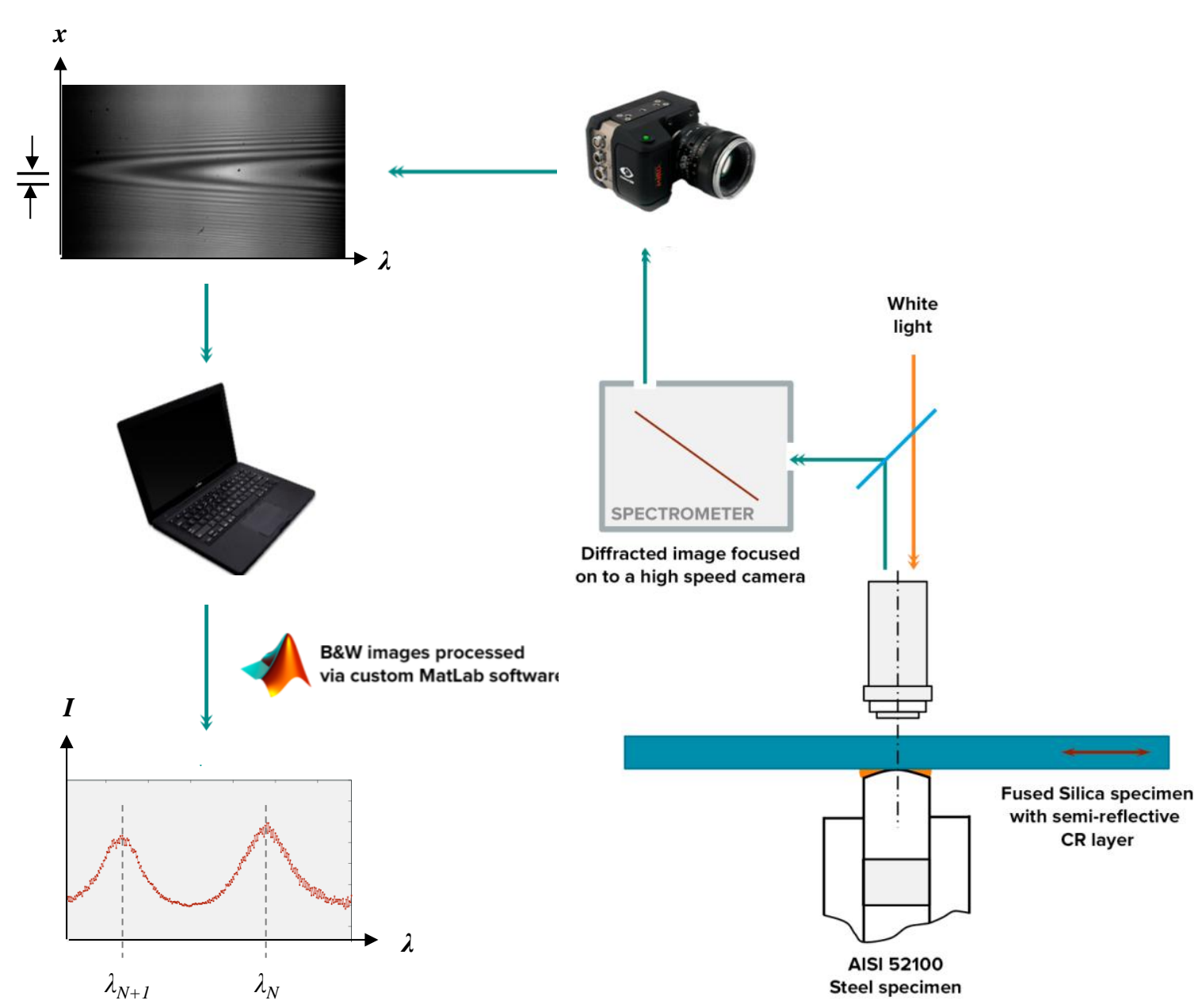
the transparent reciprocating pad. The lower surface of the pad specimen is coated with a $570 \mathrm{~nm}$ semi-reflective chromium coating so that light from the microscope undergoes a division of amplitude when it is incident on the oil film. A spectrometer slit captures the interfered reflected beam and disperses it by wavelength before being recorded by a high speed video camera. In Figure 2, an example output image from the spectrometer is shown in the top left corner, where wavelength is on the horizontal axis and distance along the contact is on the vertical axis. Here, lighter and darker regions represent constructive and destructive interference respectively. This image is then processed in Matlab to remove erroneous spectral variations (that arise from the optical system), before being averaged over its central region to give the variation in intensity versus wavelength, shown in the bottom left of the Figure. The peaks in this graph result from constructive interference of light at specific wavelengths. The following text explains the modifications to the standard ultra-thin film interferometry technique that are necessary for the type of contact being studied.

Figure 2 - Schematic diagram of the interferometry set-up

The piston-liner contact frequently operates in the mixed and boundary regimes with film thickness less than $100 \mathrm{~nm}$. Using interferometry, it is not possible to measure such thin films directly, since values in this range do not provide a sufficiently large path difference 
between the light rays to cause interference. To ensure that the optical gap between the sliding surfaces is greater than $1 / 2$ the wavelength of light, and hence cause interference fringes, a "spacer layer" is typically applied to the contacting surface of the transparent specimen. The invisible spacer layer increases the measured film thickness by virtue of having a refractive index close to that of the test lubricant and its thickness, determined prior to testing, is subtracted from each test measurement. In this work, however, a silica spacer layer had to be avoided since it would alter the topography of the pocketed surface of the transparent specimen. Furthermore, due to the sliding nature of the contact, operating under mixed lubrication conditions, any surface coatings present would be removed rapidly due to wear. Therefore, a modification was devised, in which the effect of the spacer layer was reproduced by using the out-of-contact curvature of the ring specimen - i.e., as shown in Fig. 3 , the measurement location was chosen outside the contact area so that each measurement was a composite of the lubricant film thickness and the 400 to $700 \mathrm{~nm}$ gap caused by the curvature of the ring specimen. The required curvature of the ring specimen was achieved by machine grinding a slope on to each end of the pin specimen prior to testing.

A challenge to overcome here is that, whereas a spacer layer's approximate thickness is known a priori, the out-of-contact gap is not known and therefore the fringe order is not available to be used in the film thickness calculation. To overcome this problem, a second modification was made, whereby the film thickness was calculated based on the difference in wavelength between adjacent interference fringes. The equation to enable this calculation is obtained as follows.

Constructive interference occurs when the light beam, reflecting off the lower surface of the oil film, has travelled an integer number of wavelength further than the beam reflected of the upper surface according to

$$
h=\frac{(N-\phi) \lambda_{N}}{2 n \cos \theta}
$$

where $h$ is the spatial thickness of the oil film, $n$ is its refractive index, $\lambda_{N}$ is the wavelength associated with the $N^{\text {th }}$ order fringe, $\theta$ is the angle of incidence of the oil and $\phi$ is any phase change that occurs on reflection.

If white light containing a broad range of wavelengths is used, then, for the same film thickness, $h$, Equation (1) will be satisfied for several different values of $N$. For example, some smaller wavelength, $\lambda_{N+1}$, will result in the $N^{\text {th }}+1$ interference fringe according to

$$
h=\frac{(N+1-\phi) \lambda_{N+1}}{2 n \cos \theta}
$$

If Equations (1) and (2) are equated and rearranged, an expression for $h$ is obtained in which the fringe order and the phase change are absent

$$
h=\frac{\lambda_{N} \lambda_{N+1}}{2 n\left(\lambda_{N}-\lambda_{N+1}\right)}
$$


This relationship is useful since it enables the film thickness to be calculated from the wavelengths of any two adjacent interference fringes without requiring knowledge of the phase difference or fringe order (hence overcoming the issue of "wavelength ambiguity" that is sometimes discussed (e.g. see [55]). All that is needed in practice to obtain film thickness values with this approach is an intensity-wavelength image from the spectrometer that shows more than one interference peak. Usually, this condition is satisfied when large film thicknesses are measured (since they allow many wavelengths to interfere). The out-ofcontact measurement method, described above, produces sufficiently large thickness (i.e. hundreds of $\mathrm{nm}$ ) and makes this possible.

It should be noted that Equation (3) can also be used to calculate film thickness based on two adjacent destructive interference fringes.
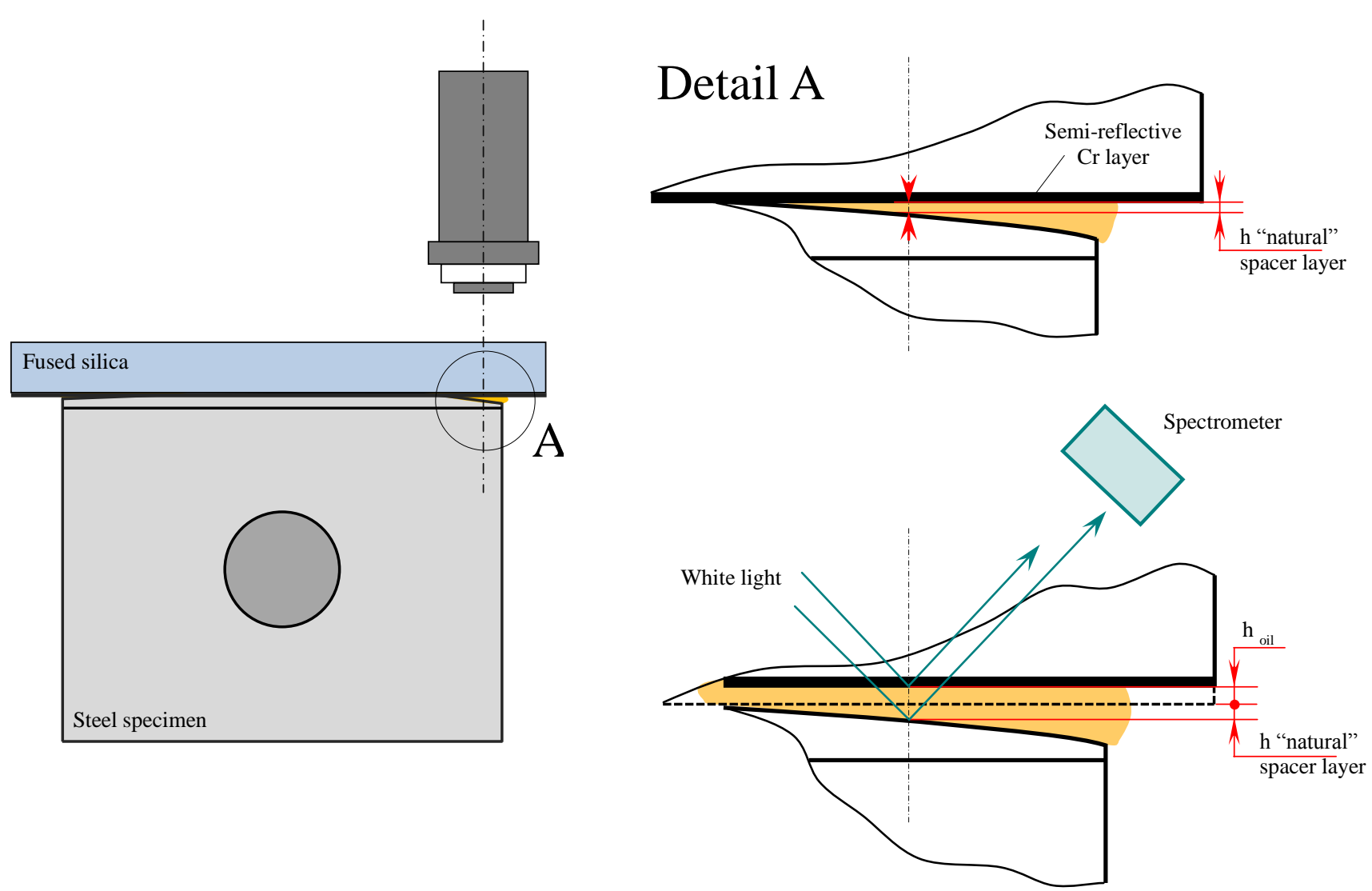

Figure 3 - Principle of ultrathin film interferometry with "natural” spacer layer

In order to measure film thickness in this way, knowledge was required of the out of contact gap at each angular position along the stroke (since it varied slightly due to imperfections in the fused silica specimen and differences in alignment between the contacting surfaces). To achieve this, successive images were recorded prior to each test, under quasi static conditions (i.e. reciprocating at a speed of $0.1 \mathrm{~Hz}$ ) and with the relevant normal load applied. A frame rate of $200 \mathrm{~Hz}$ was used here, resulting in 6 film thickness measurements for every singular angular position of the crankshaft's revolution. In this way, interference images were captured throughout four consecutive strokes (two crank 
revolutions) and were subsequently processed automatically using a custom Matlab code. This processing consisted of:

a) Averaging the two recorded strokes.

b) Calibrating out erroneous spectral intensity variations (that typically from the light source) by dividing each measured spectrum by one which had been obtained when no optical interference fringes were present (i.e. applying the same technique as that used by PCS instruments EHL ULTRA rigs),

c) Identifying the wavelengths that corresponded to adjacent interference peaks using standard Matlab peak detecting functions.

d) Applying Equation (3) to give film thickness.

The resulting variation in gap height with angular position was then stored to be used in the subsequent test (this is analogous to the spacer layer thickness being recorded in conventional thin film interferometry). Each test involved increasing the speed to the required value, acquiring images at the same out of contact location, and processing with the same Matlab code (described above) to give the film thickness variation along the stroke. Then, to obtain the in contact film thickness, the quasi static film thickness was subtracted from each test measurement at the correct angular position. This was possible, since the angular position at which each image was acquired was recorded, alongside film thickness, thanks to the trigger system and the rotary encoder.

In summary, the optical interferometry technique was selected and modified for this research for two main reasons: $i$ ) it is now believed that texture is most effective under mixed lubrication conditions $([4,8,10,12])$ where film thicknesses are in the order of nanometres and hence this technique is most effective, $i$ ) the use of conventional LIF techniques was not possible for such textured surfaces, as measurements are distorted by additional light escaping from inside the pocket which is nearly an order of magnitude deeper than the contact film thickness. It should be noted that this newly developed technique measures the average separation of the rough surfaces compared to the stationary case where these is no load support from the oil. It does not prove two dimensional maps of the film thickness.

\section{Experimental procedure and test specimens}

Real-time measurements of frictional force were acquired simultaneously with film thickness using a LabView programme. Fully formulated SAE 40 oil was supplied to the reciprocating contact, and its temperature and consequently viscosity were controlled accurately. Table 1 shows the lubricant properties for three distinct temperatures, selected in order to place the reciprocating bearing in various lubrication regimes. In one set of tests the speed was varied between $1 \mathrm{~Hz}$ and $3 \mathrm{~Hz}$ for a constant load of $10 \mathrm{~N}$, while in a second set, progressive loads $(10 \mathrm{~N}, 30 \mathrm{~N}$ and $50 \mathrm{~N})$ were applied for a constant speed of $3 \mathrm{~Hz}$. In addition to the repeated out-of-contact-film thickness calibration described in Section 3, isometric load cell calibrations were performed before and after each test sequence (for more details of the friction test procedure see [4]). 


\begin{tabular}{cccc}
\hline 15 & 273.628 & 314.913 & 0.8689 \\
\hline 45 & 61.727 & 72.603 & 0.8502 \\
\hline 80 & 18.847 & 22.753 & 0.8283 \\
\hline
\end{tabular}

Table 1 - Properties of the fully engine formulated lubricant at the desired temperatures selected for this study

A $10 \times 10 \times 2 \mathrm{~mm}$ rectangular steel pad (AISI 52100) was manufactured and fully hardened at $850 \mathrm{HV}$ to closely replicate the IC engine piston ring. A minimum stock of 0.15 $\mathrm{mm}$ was subsequently removed by grinding the pad on all sides. One surface of the $2 \mathrm{~mm}$ width side was ground at a $40 \mathrm{~mm}$ radius, in the sliding direction to produce a convex form. Both friction and film thickness relied upon a high quality of finish and this was achieved (as depicted in Figure 4), by polishing with a synthetic short nap cloth and a $0.25 \mu \mathrm{m}$ monocrystalline water based diamond spray.

\begin{tabular}{|c|}
\hline Surface Stats: \\
Ra: $13.87 \mathrm{~nm}$ \\
Rq: $17.82 \mathrm{~nm}$ \\
Rt: $580.68 \mathrm{~nm}$ \\
Measurement Info: \\
Magnification: 11.02 \\
Measurement Mode: \\
VSI \\
Sampling: $898.31 \mathrm{~nm}$ \\
Array Size: $640 \times 480$ \\
\hline
\end{tabular}

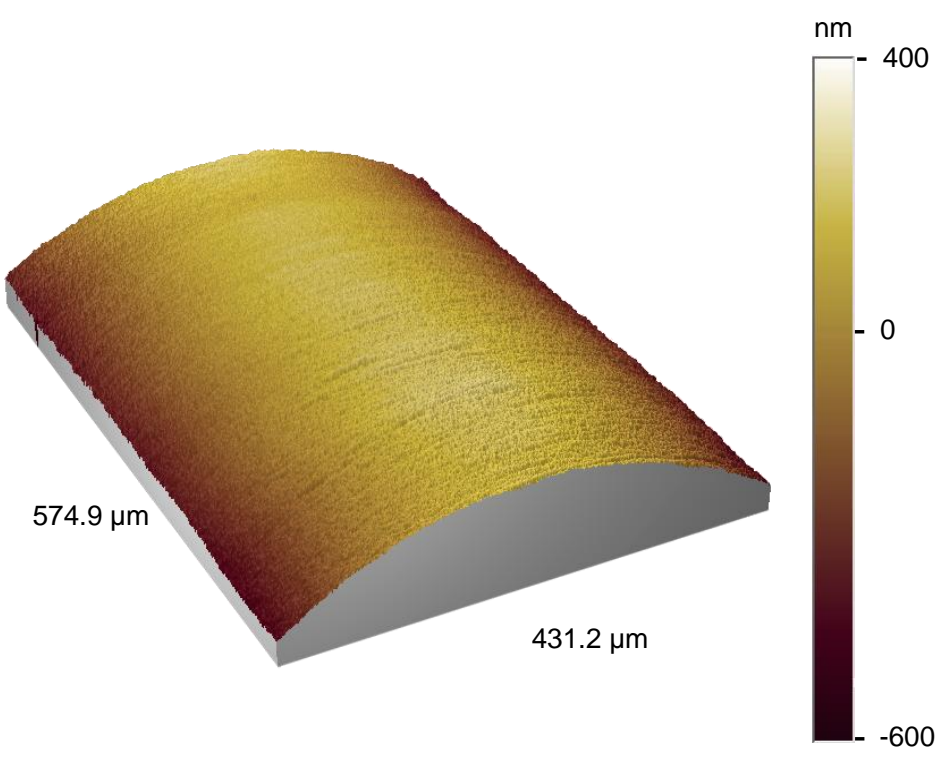

Figure 4 - Three dimensional surface topography of the cylindrical steel specimen as obtained by the Veeco Wyko NT9100 optical profiler

Due to its higher elasticity compared to normal glass (elastic modulus of $72.7 \mathrm{GPa}$ ), a HPFS Standard Grade fused silica material was selected for the flat counterpart specimen. An ultrafast laser emitting 10 picosecond optical pulses was used to texture the surface of the 
$125 \times 15 \times 5 \mathrm{~mm}$ rectangular fused silica specimen. The following performance parameters were selected for the laser texturing process: $10 \mathrm{kHz}$ frequency, $355 \mathrm{~nm}$ wavelength, 5 micro joules power. The three-dimensional optical profile of the textured sample is shown in Figure 5, as recorded by a Veeco Wyko NT9100 optical profiler. The dimensions of the pockets were $7.5 \mu \mathrm{m}$ in depth; $80 \mu \mathrm{m}$ in width; $500 \mu \mathrm{m}$ separation (gap between two lines of pockets in the direction of travel).

This pocket shape was selected based on previous experimental work carried out by the authors, which showed that transverse grooves normal to the direction of sliding exhibit the lowest friction force under mixed and boundary lubrication regimes when compared with other textured patterns such as chevron, crosshatch and grooves inclined or parallel to the direction of sliding [4].

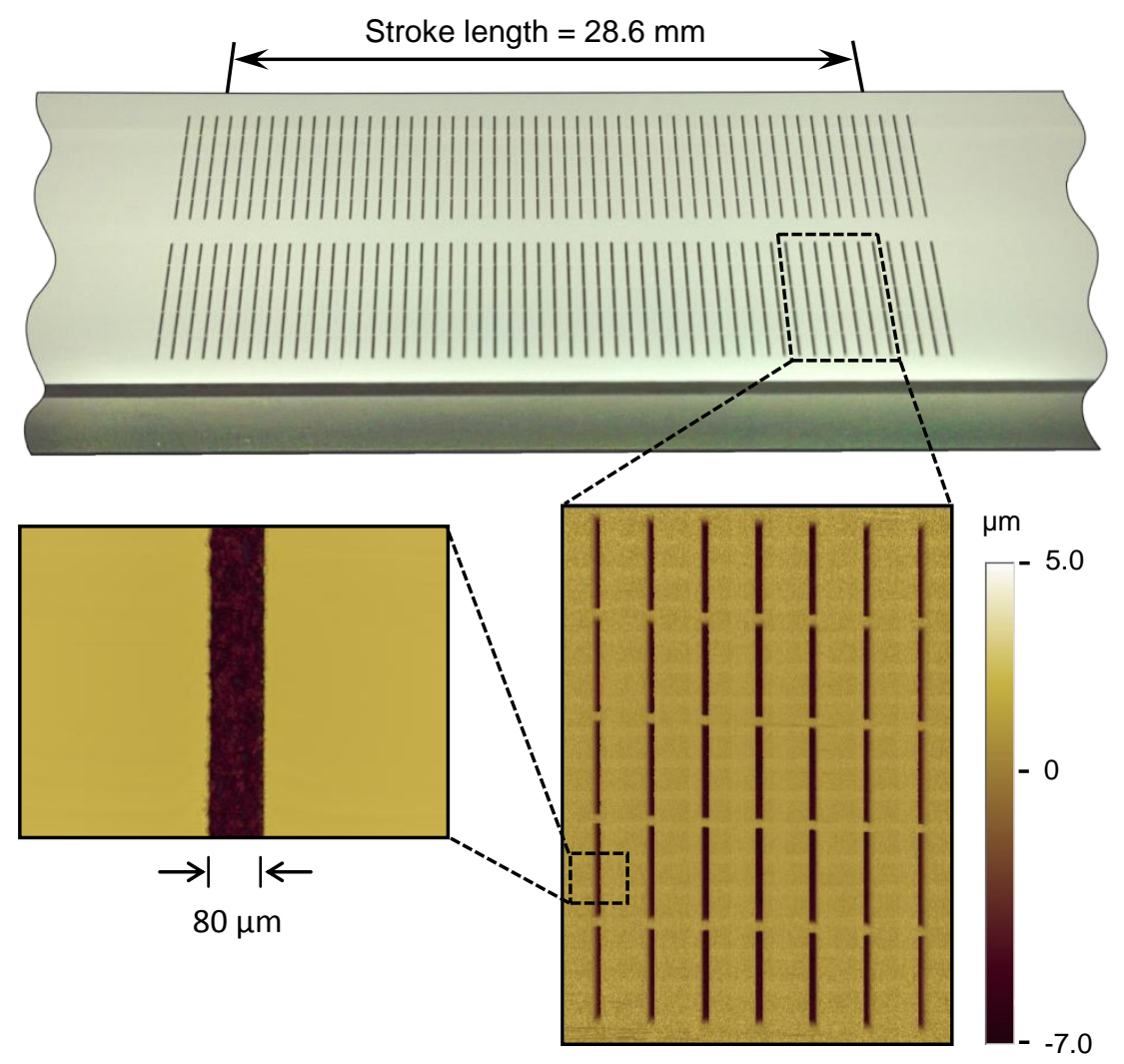

Figure 5 - Two dimensional surface plot of the laser surface textured fused silica specimen

Before starting the simultaneous film thickness-friction force test sequence, measurement repeatability and stability over time were assessed for each of the two parameters. Figure 6 demonstrates the repeatability over time for both friction force and film thickness tests for three non-consecutive measurements, performed on different days. These were performed with the non-textured specimen for one combination of test conditions (crank angular velocity: $3 \mathrm{~Hz}$, normal load: $30 \mathrm{~N}$, oil temperature: $15^{\circ} \mathrm{C}$ ). It can be seen from Fig 6 that the variation in measured film thickness is not identical for every stroke, with strokes two and four showing lower values than one and three. This erroneous variation is due to a slight rolling rotation of the pad. Measures, such as using high tolerance linear bearings and the 
self-aligning mechanism, were put in place to reduce this effect but it was not possible to remove it entirely.

In order to check the validity of these measurements, film thickness was calculated for the relevant test conditions at the midpoint along stroke (this position was chosen so as to negate transient variations due to squeeze film effects). Specifically, Dowson and Toyoda's central film thickness equation for a line contact [56] was used and the result is shown in the figure. It is clear that the calculation matches the measurement very well and thus provides some validation for this new interferometry approach.

Test No. 2

Test No. 3
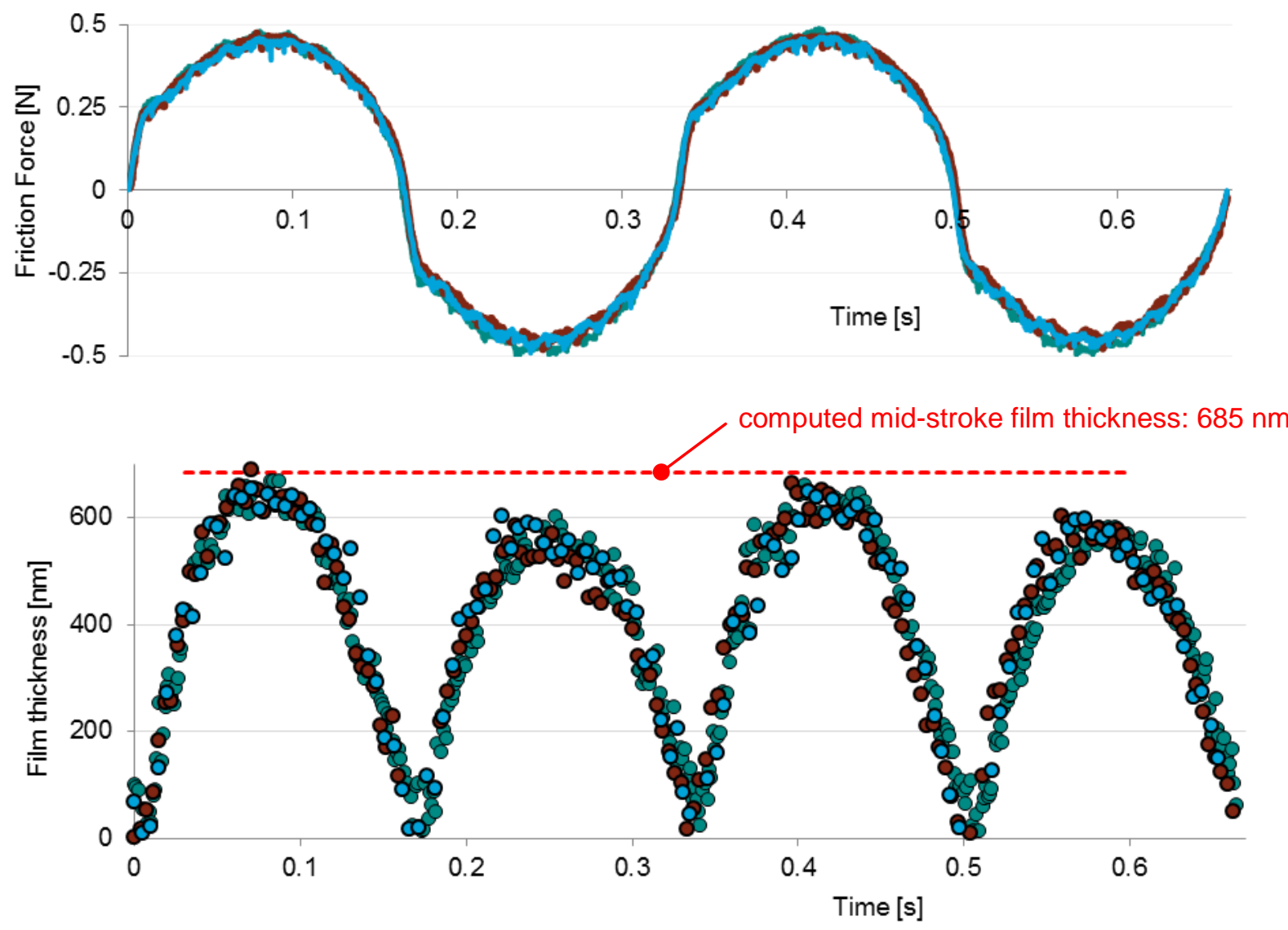

Figure 6 - Stable friction force over time for the smooth specimen; repeatability between three different tests.

\section{Results and discussion}

The graphs shown in this section clarify the relationship between friction response and stroke angle, as well as oil film thickness and stroke angle, both as a function of applied normal load and sliding speed. The section is divided up according to the test temperature, since the lubricant temperature (and hence its viscosity) controls the lambda value and therefore the lubrication regime under which the contact is operating. For each lubrication 
regime, two series of tests were performed. First, the angular velocity was varied while keeping normal applied load constant and second, the applied load was varied while keeping the crank angular velocity constant.

For each test, a comparison between the textured and non-textured specimens is presented. Both friction force and film thickness curves display cyclic fluctuations, as the sliding speed varies along the stroke length.

\subsection{Results from full film regime - nominal lambda for non-textured specimen varying between 3.6 and 7.9}

Results from the full film lubrication regime are shown in Fig. 7 and Fig. 8. Here, simultaneous friction force and film thickness test data are plotted for a constant oil temperature of $15^{\circ} \mathrm{C}$ (oil viscosity of $273.6 \mathrm{mPa} \cdot \mathrm{s}$ ) while varying the crank angular velocity (Fig. 7) and normal applied load (Fig. 8). These tests show the friction force increasing towards the middle of the stroke in an approximately sinusoidal fashion. This occurs because under such conditions, friction arises due to the shearing of oil layers inside the contact, and is approximately proportional to the varying sliding velocity. This has been noted previously by the current authors in [4], and is in good agreement with observations by Costa and Hutchings [30]. Also in agreement with hydrodynamic/elastohydrodynamic theory, it can be observed that both friction and film thickness increase with reciprocating frequency and hence entrainment speed. 

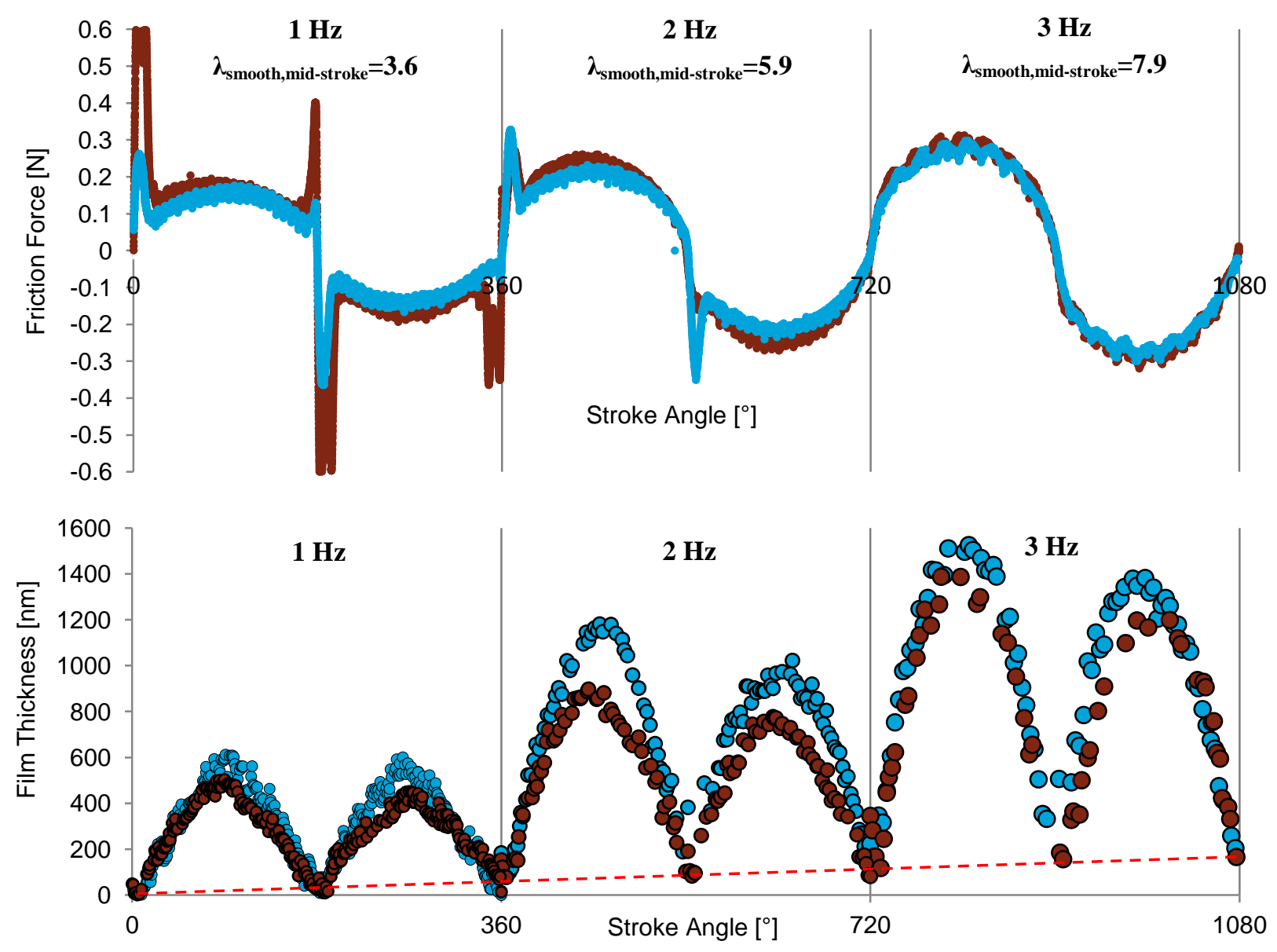

Figure 7 - Simultaneous measured friction force and film thickness comparisons between textured and nontextured samples under full film lubrication regime (test conditions: crank angular velocity: 1, 2 and $3 \mathrm{~Hz}$, normal load: $10 \mathrm{~N}$, oil temperature: $15^{\circ} \mathrm{C}$ )

From Fig. 7 (and also 8) it can clearly be observed that the presence of surface texture in the full film regime results in higher friction compared with the non-textured case. These friction results support the conclusions from previous study, conducted by the current authors [4] where it was shown that in the full film lubrication regime the surface texture is detrimental, no matter which of the tested pocket geometries or patterns are used. Furthermore, the film thickness measurements in Fig. 7 and Fig. 8 show that this friction increase is caused by an increase in shear rate. The current friction plots are also in agreement with those obtained by Kovalchenko et al. [8], Pettersson and Jacobson [20] and Costa and Hutchings [30], in that the presence of surface texture does not significantly reduce friction force when a bearing is fully lubricated. 

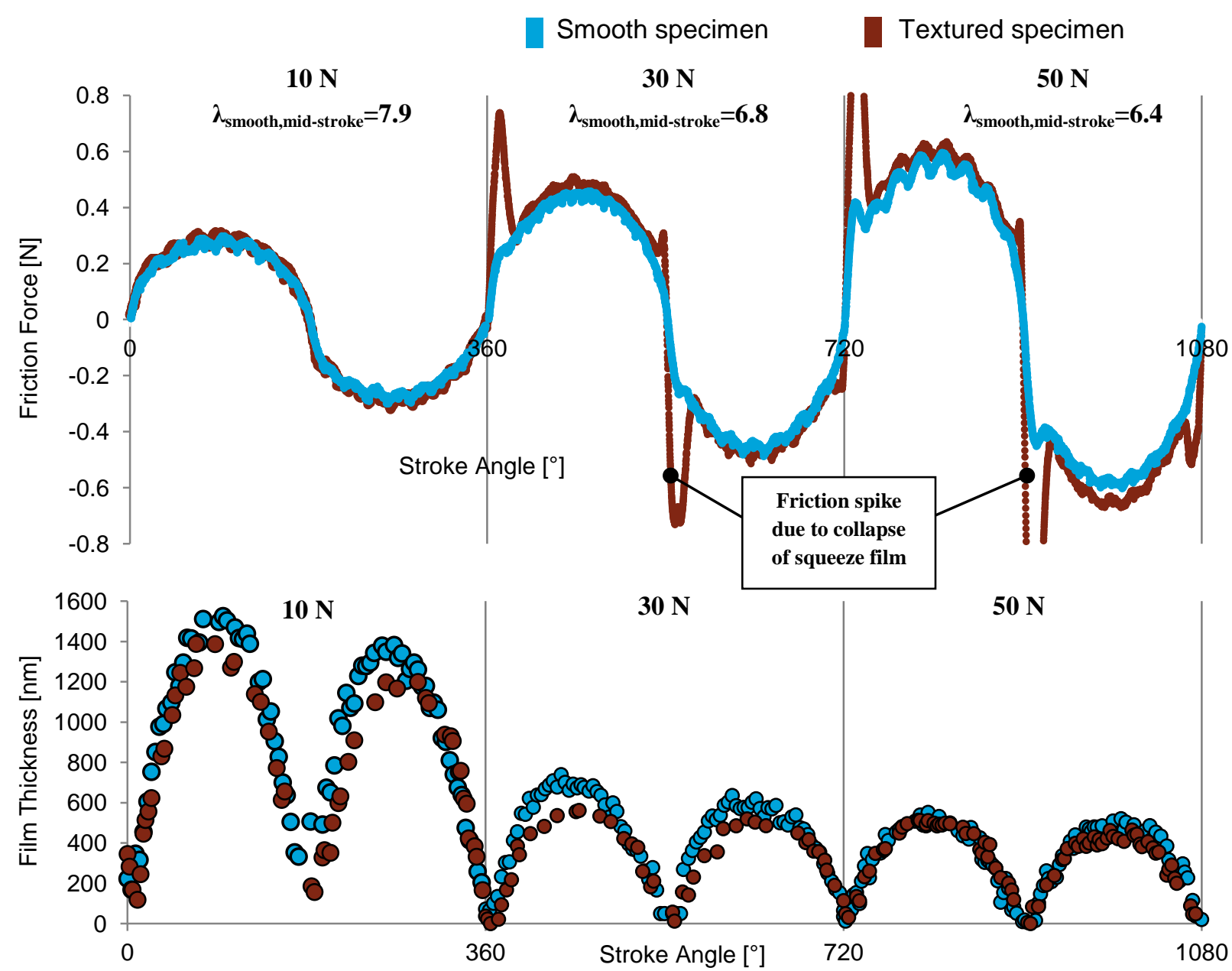

Figure 8 -Simultaneous friction force and film thickness comparisons between textured and non-textured samples under the full film lubrication regime (test conditions: crank angular velocity: $3 \mathrm{~Hz}$, normal load: 10, 30 and $50 \mathrm{~N}$, oil temperature: $15^{\circ} \mathrm{C}$ )

Fig. 8 shows how friction force and film thickness vary with applied normal load, when the angular speed is held constant at $3 \mathrm{~Hz}$. Although friction is seen to increase with applied load, the coefficient of friction reduces again according to hydrodynamic theory (i.e. $\mu \alpha \mathrm{u} / \mathrm{h}$ and $\mathrm{h} \alpha \mathrm{w}^{-0.5}$, therefore $\mu \alpha \mathrm{w}^{-0.5}$ ). This is confirmed by a simple analysis of the data in Fig. 8, which shows that the coefficient of friction at mid-stroke is approximately proportional to the load raised to the power 0.5 .

Similar to Fig. 7, Fig. 8 again shows that surface texture has a detrimental effect on film thickness in the full film regime.

The detrimental effect of texture features being present at the reversal point, and protruding outside the contact area, is demonstrated by Figs. 7 and 8. Here, pockets act to collapse the squeeze film, thus causing a pronounced friction spike as the contact enters into mixed/boundary regime.

Fig. 8 also shows that, although for the textured specimen the friction spike after reversal is significantly higher than that of the smooth specimen, the friction force falls rapidly to the same level as, or even below, the non-textured value as the contact accelerates (test condition: $30 \mathrm{~N}$ and $50 \mathrm{~N}$ ). However, towards the middle of the stroke, the friction response of the textured specimen increases above the non-textured value. 
A final detail to be noted from Fig. 7 is

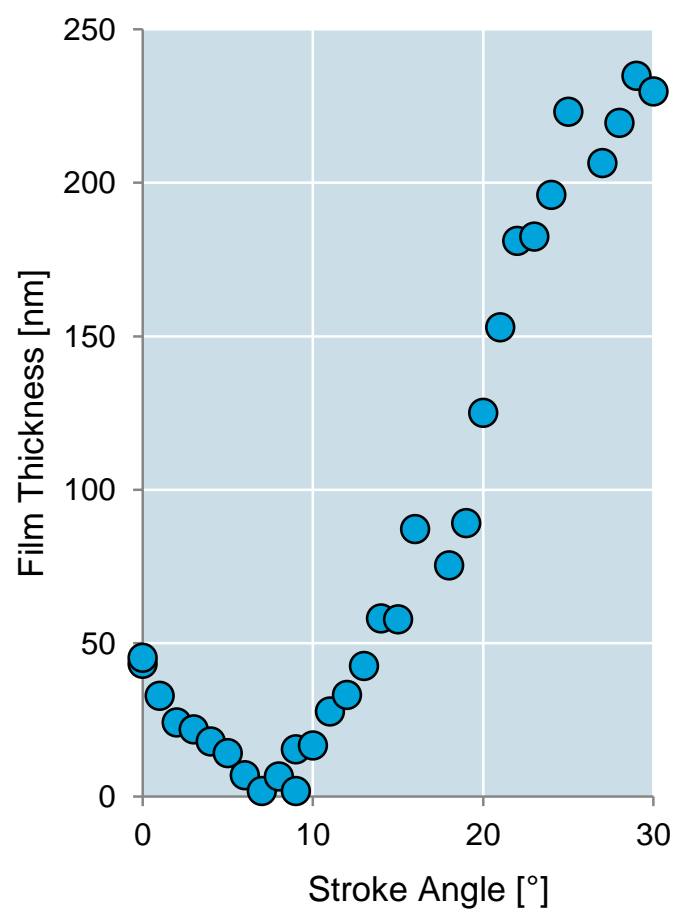

the minimum film thickness is reached at $8^{\circ}$ of crankshaft revolution after the reversal point. This is when the rate of film reduction due to the lubricant being squeezed out from the contact is outweighed by the increasing thickness due to hydrodynamic entrainment. The film thickness in Fig. 9(a) was used to calculate the strain rate $(u / h)$, which is shown in Fig. 9(b), alongside the measured friction force. As expected, the maximum friction coincides with the maximum strain rate (since, under hydrodynamic conditions, friction is proportional to $u / h$ ).

A final remark relating to squeeze film effects is that the film thickness peaks are not symmetrical about the maximum value. In fact, it can be seen that the film thickness during deceleration is greater than during acceleration.

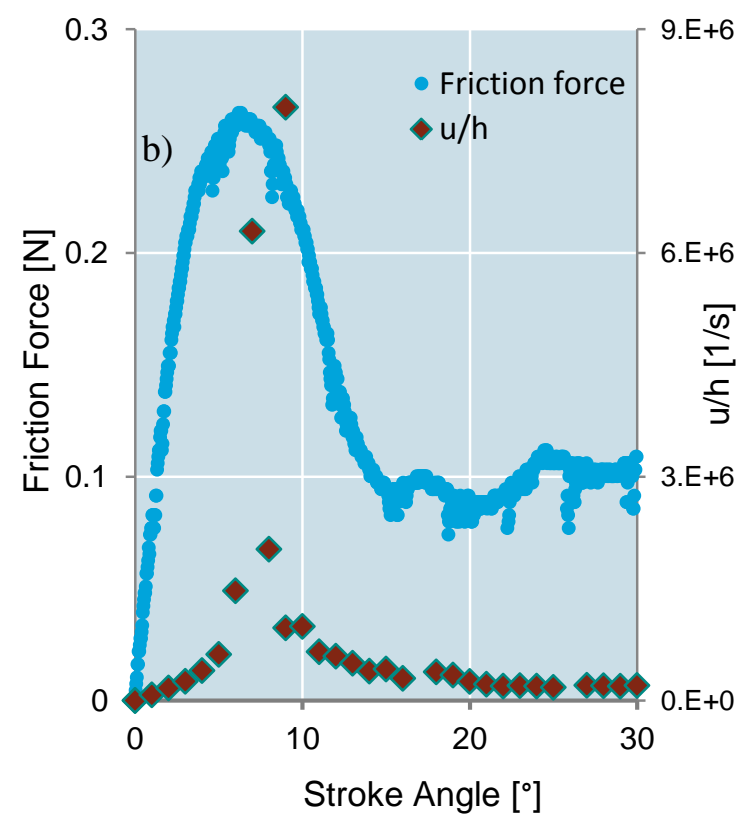

Figure 9-Oil film thickness $(a)$ and corresponding friction force $(b)$ captured for the non-textured specimen (test condition: crank angular velocity: $1 \mathrm{~Hz}$, normal load: 10 $N$, oil temperature: $15^{\circ} \mathrm{C}$ )

This is because, during deceleration, squeeze effects prevent the film falling to its steady-state value, while, during acceleration, the converse effect prevents the film thickness reaching its steady-state value (the behaviour has been observed previously by Costa and Hutchings [30] and predicted recently by Medina et al [57]).

\subsection{Results from mixed regime - nominal lambda for non-textured specimen varying between 1.3 and 2.8}


When the lubricant temperature is increased to $45^{\circ} \mathrm{C}$ (oil viscosity: $61.73 \mathrm{mPa} \cdot \mathrm{s}$ ), the bearing contact under investigation passed from the full film lubrication regime towards the mixed regime (as the lambda value reduced). As shown previously in [4], friction values obtained around the centre of the stroke are not affected by squeeze effects and may therefore be plotted onto a master Stribeck curve. When this is done for both smooth and textured specimens, it can be seen that the latter has the effect of shifting the Stribeck curve towards the left, and this was previously attributed to an increased oil film thickness in the mixed regime [4]. This hypothesis has been confirmed in the current study by the simultaneous measurement of friction force and oil film thickness for the test conditions corresponding to the transition from full film to mixed lubrication (Fig. 10 and Fig. 11).
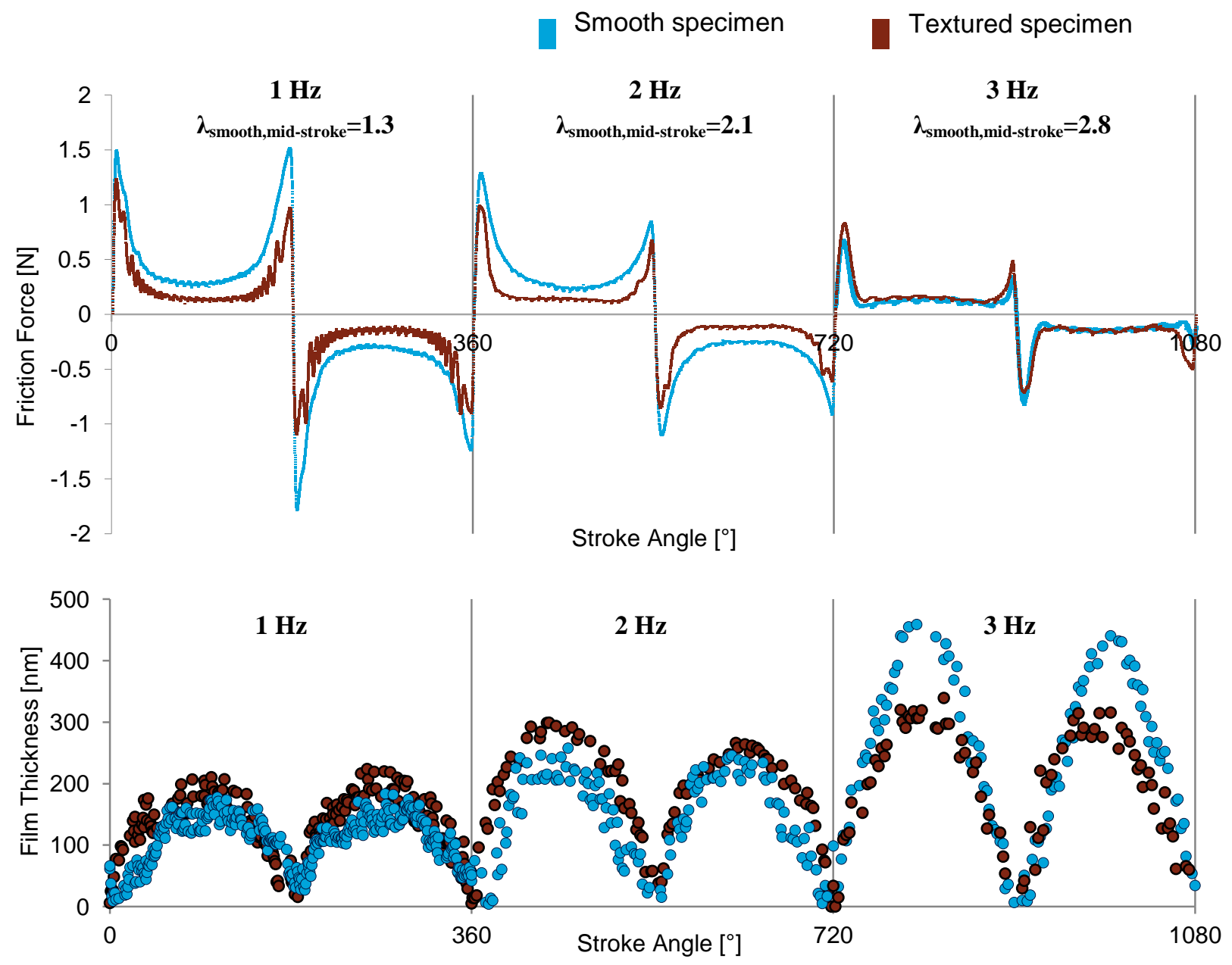

Figure 10 - Simultaneous friction force and film thickness measurements, comparing textured and non-textured samples and showing the transition from mixed to full film lubrication (test conditions: crank angular velocity: 1, 2 and $3 \mathrm{~Hz}$, normal load: $10 \mathrm{~N}$, oil temperature: $45^{\circ} \mathrm{C}$ )

As depicted in Fig. 10, the friction force for the non-textured specimen reduces with increasing reciprocating speed as a result of the contact moving from the mixed to the full film regime. The textured specimen on the other hand is less affected by the variation in reciprocating speed and as a result, there is a cross over between the friction results for the two specimens - at both 1 and $2 \mathrm{~Hz}$ the textured specimen out performs the non-textured, while at $3 \mathrm{~Hz}$, the reverse is true. This is because at 1 and $2 \mathrm{~Hz}$, the contact is operating in the mixed regime, where texture is known to be effective, while at $3 \mathrm{~Hz}$ the contact is 
operating in the full fill regime, where texture is detrimental. The corresponding film thickness results are in complete agreement with the friction results, in that the higher friction between textured and non-textured is invariably accompanied by a lower film thickness - i.e. in the mixed regime, texture increases film thickness and hence reduces asperity contact and, in turn, friction; while in the full film regime, texture reduces film thickness and hence increases shear rate and, in turn, friction.

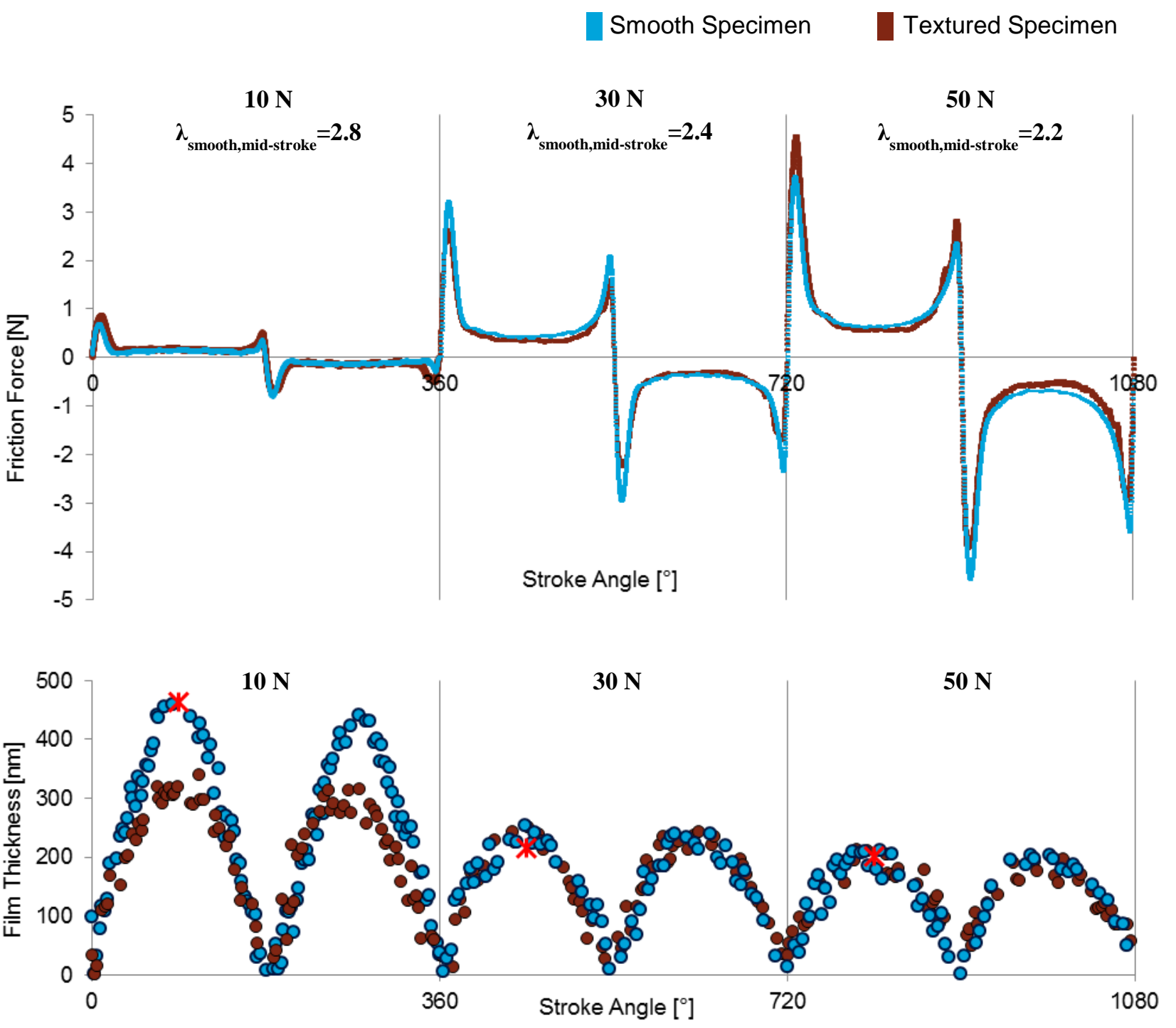

Figure 11 - Simultaneous friction force and film thickness measurements, comparing textured and nontextured samples and showing the transition from full film to mixed lubrication (test conditions: crank angular velocity: $3 \mathrm{~Hz}$, normal load: 10, 30 and $50 \mathrm{~N}$, oil temperature: $45^{\circ} \mathrm{C}$ ). Red asterisks denote film thickness, calculated according to[56,58]

Fig. 11 shows the effect of applied load for the oil at $45^{\circ} \mathrm{C}$. Here, the transition from full film to mixed lubrication can again be seen, however, unlike Fig. 10, the beneficial effects of texture in the mixed regime are markedly less pronounced. The behaviour is tentatively attributed to the sliding speed effecting, not only the lubrication regime, but also the frequency with which the pockets are entrained in to the contact. As will be explored in future work, the pocket entrainment frequency is believed by the authors to being a key parameter in controlling the effectiveness of surface texture friction reduction. 
A large change in film thickness is evident in Figs. 10 and 11 when comparing the 3 $11)$.

This can be attributed to a change in elastohydrodynamic lubrication regime specifically, the bearing is running under rigid-isoviscous lubrication conditions for the $3 \mathrm{~Hz}-$ $10 \mathrm{~N}$ test and under piezoviscous-elastic conditions for the $30 \mathrm{~N}$ and $50 \mathrm{~N}$ tests. This change in lubrication regime was verified by applying Johnson's method [59] to each set of test conditions and was further confirmed when the calculated film thicknesses (based on the appropriate lubricant regime) agreed closely with the experimental values in Fig. 11 (see red asterisks on the figure).

\subsection{Results from mixed/boundary regime - nominal lambda for non-textured specimen varying between 0.9 and 1.2}

Finally, the oil temperature was increased to $80^{\circ} \mathrm{C}$ (oil viscosity: $18.85 \mathrm{mPa} \cdot \mathrm{s}$ ) and friction force was recorded simultaneously with the oil film thickness response (Fig. 12). Angular velocity was kept constant at $3 \mathrm{~Hz}$, while the applied normal load was varied from $10 \mathrm{~N}$, to $30 \mathrm{~N}$ and $50 \mathrm{~N}$. Here, friction reductions of up to $41 \%$ were recorded when comparing the textured and non-textured specimens. Although oil film thickness measurements were difficult under these extreme testing conditions due to vibration, data captured during four consecutive strokes were averaged and plotted against stroke angle. It can be seen that there is only a slight $(\sim 20 \mathrm{~nm})$ difference in film thickness between the textured and non-textured specimens. At first sight, this is surprising, given the large difference in friction force between the two. However, it should be noted that these contacts are operating in the mixed lubrication regime, where friction is highly sensitive to film thickness changes, due to the steep gradient of the Stribeck curve. 

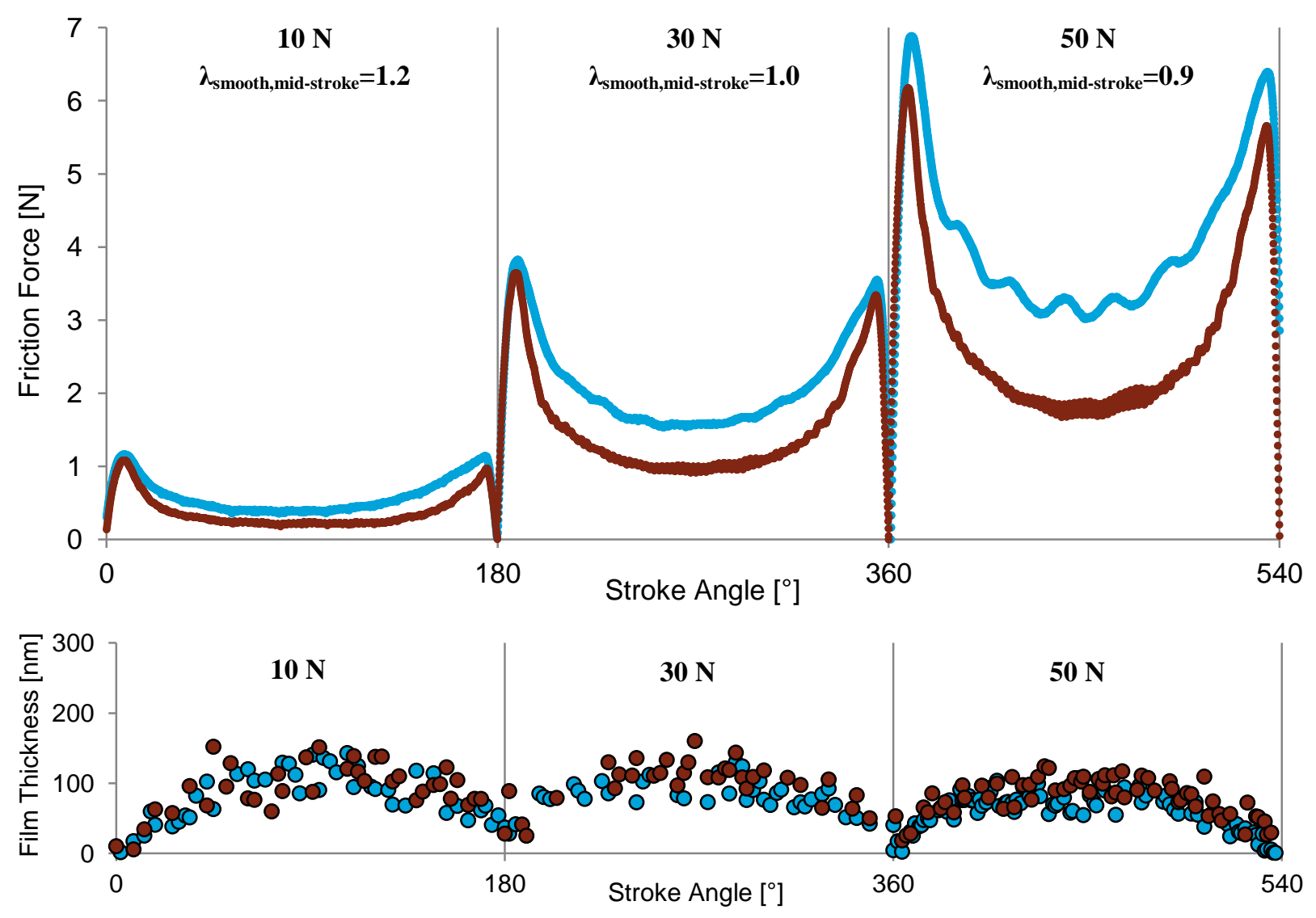

Figure 12 - Simultaneous friction force and film thickness measurements, comparing textured and non-textured samples in the mixed lubrication regime (test conditions: crank angular velocity: $3 \mathrm{~Hz}$, normal load: 10, 30 and $50 \mathrm{~N}$, oil temperature: $80^{\circ} \mathrm{C}$ ) 


\subsection{Summary of Results}

The method described above, of plotting mid-stroke friction force from different reciprocating tests onto a single master Stribeck curve, was applied to the data in Figs 8, 11 and 12. The result of this is shown in Fig. 13 (for a range of loads and an angular velocity of $3 \mathrm{~Hz}$ ), where it can be seen clearly that the effect of texture is to reduce friction in mixed and boundary regime. In addition, at $45^{\circ} \mathrm{C}$ the transition between mixed and full film lubrication occurs and this further explains the reversal in texture vs. non-textured performance, observed in Figure 10.

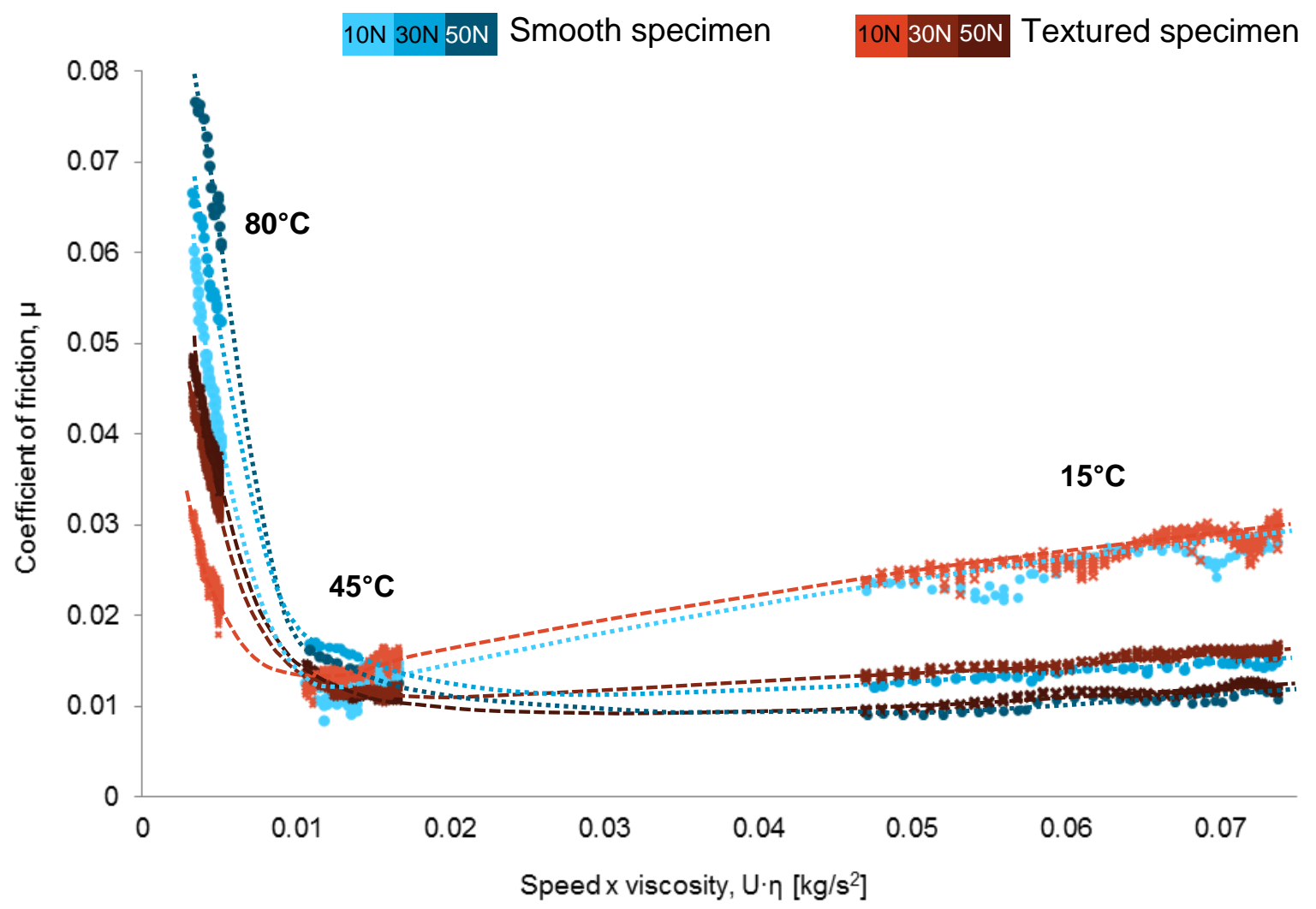

Figure 13 - Stribeck curves showing friction behaviour at the following oil temperatures: $15^{\circ} \mathrm{C}, 14^{\circ} \mathrm{C}$ and $80^{\circ} \mathrm{C}$. Sliding velocity was kept constant, while load was varied from $10 \mathrm{~N}$ to $30 \mathrm{~N}$ and $50 \mathrm{~N}$.

For a better understanding of the influence of texture in the mixed regime, friction data recorded for all three test conditions presented in Fig. 12 (oil temperature: $80^{\circ} \mathrm{C}$, oil viscosity: $18.85 \mathrm{mPa} \cdot \mathrm{s}$ ) were plotted against film thickness in Fig. 14 (to avoid transient squeeze film effects, only data captured between $8^{\circ}$ and $90^{\circ}$ is plotted). Despite the scatter it can be seen that both textured and non-textured friction values show nearly identical dependence on film thickness. This shows that, under the conditions tested, texture-induced friction reduction results entirely from the increase in film thickness. 


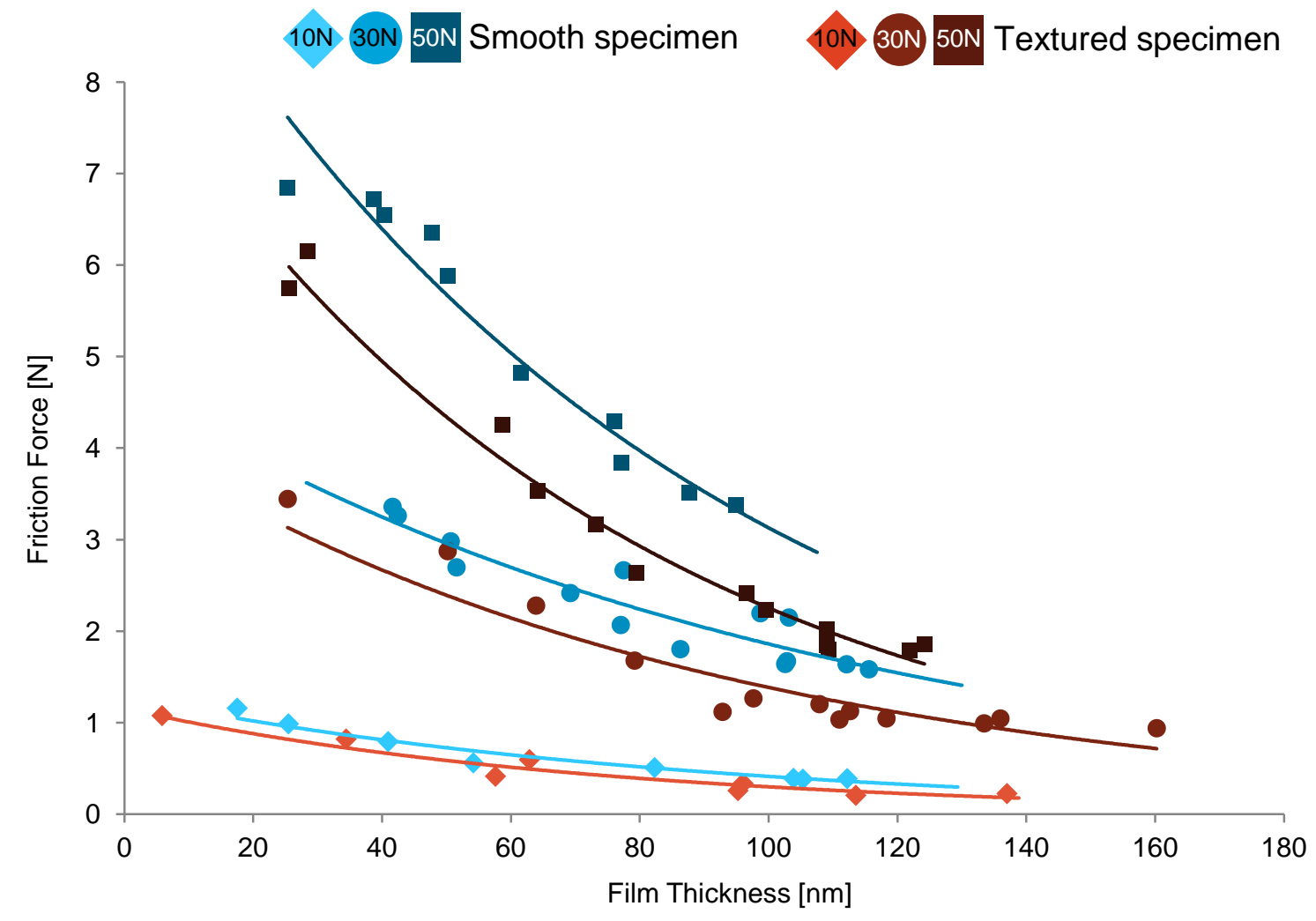

Figure 14 - Friction force variation vs. oil film thickness for three different loading conditions: $10 \mathrm{~N}, 30 \mathrm{~N}$ and $50 \mathrm{~N}$ (crank angular velocity: $3 \mathrm{~Hz}$, oil temperature: $80^{\circ} \mathrm{C}$ )

\section{Conclusions}

This paper contributes to the field of tribology research in two ways. Firstly, it demonstrates how a modified version of ultrathin film interferometry can be used to measure transient changes in film thickness under sliding, mixed lubrication conditions. The approach uses the out-of-contact curvature of the specimens in order to negate the need for a spacer layer and analyses multiple interference fringes to remove fringe ambiguity. This enabled film thickness to be measured in a reciprocating line contact, replicating the piston ring-liner pairing. The validity of the technique was confirmed by a comparison with standard HL and EHL theory; its key benefits include:

- The ability to study transient film behaviour in detail. For instance, the squeeze effect was seen to preserve the film thickness at reversal so that the minimum lubricant thickness occurred after $8^{\circ}$ to $10^{\circ}$ of angular revolution into the subsequent stroke and coincided with the peak in friction force. This can be used to test hypotheses regarding optimum ring geometry [60].

- The production of data to validate transient piston ring modelling, such as [57].

The second contribution of the paper is its evaluation of the beneficial and detrimental effects of laser surface texture by simultaneously measuring friction force and lubricant film behaviour in a line contact placed under different lubrication regimes. 
Considering that an IC engine's piston transits all three lubrication regimes over one

\section{Acknowledgement}

The authors are grateful to Khizer Tufail and Arup Gangopadhyay for their advice and support. The project was funded by the Ford Motor Company.

\section{References}

[1] Goldstein S. Modern developments in fluid mechanics. Dover Publ New York 1965:702.

[2] Daniel TL. Fish mucus: in situ measurements of polymer drag reduction. Biol Bull 1981;160:376-82.

[3] Sun M, Luo C, Xu L, Ji H, Ouyang Q, Yu D, et al. Artificial lotus leaf by nanocasting. Langmuir 2005;21:8978-81. doi:10.1021/la050316q.

[4] Vlădescu S-C, Olver A V., Pegg IG, Reddyhoff T. The effects of surface texture in reciprocating contacts - An experimental study. Tribol Int 2015;82:28-42. doi:10.1016/j.triboint.2014.09.015.

[5] Ryk G, Etsion I. Testing piston rings with partial laser surface texturing for friction reduction. Wear 2006;261:792-6. doi:10.1016/j.wear.2006.01.031.

[6] Etsion I, Sher E. Improving Fuel Efficiency with Laser Surface Textured Piston Rings. Tribol Int 2009;42:542-7. doi:10.1016/j.triboint.2008.02.015.

[7] Rahnejat H, Balakrishnan S, King PD, Howell-Smith S. In-Cylinder Friction Reduction Using a Surface Finish Optimization Technique. Proc Inst Mech Eng Part D J Automob Eng 2006;220:1309-18. doi:10.1243/09544070JAUTO282. 
[8] Kovalchenko A, Ajayi O, Erdemir A, Fenske G, Etsion I. The Effect of Laser Surface Texturing on Transitions in Lubrication Regimes During Unidirectional Sliding Contact. Tribol Int 2005;38:219-25. doi:10.1016/j.triboint.2004.08.004.

[9] Borghi A, Gualtieri E, Marchetto D, Moretti L, Valeri S. Tribological effects of surface texturing on nitriding steel for high-performance engine applications. Wear 2008;265:1046-51. doi:10.1016/j.wear.2008.02.011.

[10] Braun D, Greiner C, Schneider J, Gumbsch P. Efficiency of laser surface texturing in the reduction of friction under mixed lubrication. Tribol Int 2014;77:142-7. doi:10.1016/j.triboint.2014.04.012.

[11] Wang W, Huang Z, Shen D, Kong L, Li S. The Effect of Triangle-Shaped Surface Textures on the Performance of the Lubricated Point-Contacts. J Tribol 2013;135:021503. doi:10.1115/1.4023206.

[12] Lu X, Khonsari MM. An Experimental Investigation of Dimple Effect on the Stribeck Curve of Journal Bearings. Tribol Lett 2007;27:169-76. doi:10.1007/s11249-007-9217-x.

[13] Olver AV, Fowell MT, Spikes HA, Pegg IG. "Inlet suction", a load support mechanism in nonconvergent, pocketed, hydrodynamic bearings. Proc Inst Mech Eng Part J J Eng Tribol 2006;220:105-8. doi:10.1243/13506501JET168.

[14] Fowell M, Olver AV, Gosman AD, Spikes HA, Pegg IG. Entrainment and Inlet Suction: Two Mechanisms of Hydrodynamic Lubrication in Textured Bearings. J Tribol 2007;129:336-47. doi:10.1115/1.2540089.

[15] Scaraggi M, Mezzapesa FP, Carbone G, Ancona A, Tricarico L. Friction Properties of Lubricated LaserMicroTextured-Surfaces: An Experimental Study from Boundary- to Hydrodynamic-Lubrication. Tribol Lett 2012;49:117-25. doi:10.1007/s11249-012-0045-2.

[16] Wang L. Use of structured surfaces for friction and wear control on bearing surfaces. Surf Topogr Metrol Prop 2014;2:043001. doi:10.1088/2051-672X/2/4/043001.

[17] Zum Gahr KH, Mathieu M, Brylka B. Friction control by surface engineering of ceramic sliding pairs in water. Wear 2007;263:920-9. doi:10.1016/j.wear.2006.11.024.

[18] Varenberg M, Halperin G, Etsion I. Different aspects of the role of wear debris in fretting wear. Wear 2002;252:902-10.

[19] Volchok A, Halperin G, Etsion I. The effect of surface regular microtopography on fretting fatigue life. Wear 2002;253:509-15. doi:10.1016/S0043-1648(02)00148-5.

[20] Pettersson U, Jacobson S. Friction and Wear Properties of Micro Textured DLC Coated Surfaces in Boundary Lubricated Sliding. Tribol Lett 2004;17:553-9. doi:10.1023/B:TRIL.0000044504.76164.4e.

[21] Blatter A, Maillat M, Pimenov SM, Shafeev GA, Simakin AV, Loubnin EN. Lubricated sliding performance of laser-patterned sapphire. Wear 1999;232:226-30. doi:10.1016/S0043-1648(99)00150-7.

[22] Chiu YP. An Analysis and Prediction of Lubricant Film Starvation in Rolling Contact Systems. A S L E Trans 2008;17:22-35. doi:10.1080/05698197408981435. 
[23] Demirci I, Mezghani S, Yousfi M, Zahouani H, Mansori M El. The Scale Effect of Roughness on Hydrodynamic Contact Friction. Tribol Trans 2012;55:705-12. doi:10.1080/10402004.2012.694990.

[24] Krupka I, Vrbka M, Hartl M. Effect of surface texturing on mixed lubricated non-conformal contacts. Tribol Int 2008;41:1063-73. doi:10.1016/j.triboint.2007.11.016.

[25] Greiner C, Schafer M, Popp U, Gumbsch P. Contact Splitting and the Effect of Dimple Depth on Static Friction of Textured Surfaces. Appl Mater Interfaces 2014;6:7986-90.

[26] Flores G. Tribologisch gestaltete Oberflächen durch Laserstrukturieren. 2014.

[27] Costa H, Hutchings I. Some innovative surface texturing techniques for tribological purposes. Proc Inst Mech Eng Part J J Eng Tribol 2014. doi:10.1177/1350650114539936.

[28] Hamilton DB, Walowit JA, Allen CM. A Theory of Lubrication by Micro- irregularities. Trans ASME J Basic Eng 1966;88:177-85.

[29] Anno JN, Walowit J a., Allen CM. Microasperity Lubrication. J Lubr Technol 1968;90:351-5. doi:10.1115/1.3601568.

[30] Costa HL, Hutchings IM. Hydrodynamic lubrication of textured steel surfaces under reciprocating sliding conditions. Tribol Int 2007;40:1227-38. doi:10.1016/j.triboint.2007.01.014.

[31] Ronen A, Etsion I, Kligerman Y. Friction-Reducing Surface-Texturing in Reciprocating Automotive Components. Tribol Trans 2001;44:359-66. doi:10.1080/10402000108982468.

[32] Etsion I. State of the Art in Laser Surface Texturing. J Tribol 2005;127:248. doi:10.1115/1.1828070.

[33] Ryk G, Kligerman Y, Etsion I. Experimental Investigation of Laser Surface Texturing for Reciprocating Automotive Components. Tribol Trans 2002;45:444-9.

[34] Brajdic-Mitidieri P, Gosman AD, Ioannides E, Spikes HA. CFD Analysis of a Low Friction Pocketed Pad Bearing. J Tribol 2005;127:803-12. doi:10.1115/1.2032990.

[35] Fowell MT, Medina S, Olver AV, Spikes HA, Pegg IG. Parametric study of texturing in convergent bearings. Tribol Int 2012;52:7-16. doi:10.1016/j.triboint.2012.02.013.

[36] Krupka I, Hartl M, Zimmerman M, Houska P, Jang S. Effect of surface texturing on elastohydrodynamically lubricated contact under transient speed conditions. Tribol Int 2011;44:114450. doi:10.1016/j.triboint.2011.05.005.

[37] Mourier L, Mazuyer D, Ninove F-P, Lubrecht AA. Lubrication mechanisms with laser-surface-textured surfaces in elastohydrodynamic regime. Proc Inst Mech Eng Part J J Eng Tribol 2010;224:697-711. doi:10.1243/13506501JET771.

[38] Costa HL, Hutchings IM. Effects of die surface patterning on lubrication in strip drawing. J Mater Process Technol 2009;209:1175-80. doi:10.1016/j.jmatprotec.2008.03.026.

[39] Wakuda M, Yamauchi Y, Kanzaki S, Yasuda Y. Effect of surface texturing on friction reduction 
between ceramic and steel materials under lubricated sliding contact. Wear 2003;254:356-63. doi:10.1016/S0043-1648(03)00004-8.

[40] Pettersson U, Jacobson S. Influence of surface texture on boundary lubricated sliding contacts. Tribol Int 2003;36:857-64. doi:10.1016/S0301-679X(03)00104-X.

[41] Wang QJ, Zhu D. Virtual Texturing: Modeling the Performance of Lubricated Contacts of Engineered Surfaces. J Tribol 2005;127:722. doi:10.1115/1.2000273.

[42] Kirk MT. Hydrodynamic Lubrication of "Perspex.” Nature 1962;194:965-6.

[43] Cann PM, Spikes H a., Hutchinson J. The Development of a Spacer Layer Imaging Method (SLIM) for Mapping Elastohydrodynamic Contacts. Tribol Trans 1996;39:915-21. doi:10.1080/10402009608983612.

[44] Spikes H a, Cann PM. The development and application of the spacer layer imaging method for measuring lubricant film thickness. Proc Inst Mech Eng Part J J Eng Tribol 2001;215:261-77. doi:10.1243/1350650011543529.

[45] Křupka I, Hartl M. The effect of surface texturing on thin EHD lubrication films. Tribol Int 2007;40:1100-10. doi:10.1016/j.triboint.2006.10.007.

[46] Kaneta M, Todoroki H, Nishikawa H, Kanzaki Y, Kawahara Y. Tribology of Flexible Seals for Reciprocating Motion. J Tribol 2000;122:787. doi:10.1115/1.1310573.

[47] Reddyhoff T, Choo JH, Spikes H a., Glovnea RP. Lubricant flow in an elastohydrodynamic contact using fluorescence. Tribol Lett 2010;38:207-15. doi:10.1007/s11249-010-9592-6.

[48] Myant C, Reddyhoff T, Spikes H a. Laser-induced fluorescence for film thickness mapping in pure sliding lubricated, compliant, contacts. Tribol Int 2010;43:1960-9. doi:10.1016/j.triboint.2010.03.013.

[49] Dearlove J, Cheng WK. Simultaneous piston ring friction and oil film thickness measurements in a reciprocating test rig. SAE Trans J Fuels Lubr 1995;104:1452-62. doi:10.4271/952470.

[50] Dwyer-Joyce RS, Reddyhoff T, Drinkwater BW. Operating Limits for Acoustic Measurement of Rolling Bearing Oil Film Thickness. Tribol Trans 2004;47:366-75. doi:10.1080/05698190490455410.

[51] Reddyhoff T, Kasolang S, Dwyer-Joyce RS, Drinkwater BW. The phase shift of an ultrasonic pulse at an oil layer and determination of film thickness 2005;219:387-400. doi:10.1243/135065005x34044.

[52] Avan EY, Mills R, Dwyer-Joyce R. Ultrasonic Imaging of the Piston Ring Oil Film During Operation in a Motored Engine-Towards Oil Film Thickness Measurement. SAE Int J Fuels Lubr 2010;3:786-93.

[53] Mills RS, Avan EY, Dwyer-Joyce RS. Piezoelectric sensors to monitor lubricant film thickness at piston-cylinder contacts in a fired engine. J Eng Tribol 2012;0:1-12. doi:10.1177/135065011246483.

[54] Dwyer-Joyce RS, Reddyhoff T, Zhu J. Ultrasonic Measurement for Film Thickness and Solid Contact in Elastohydrodynamic Lubrication 2011;133:1-11. doi:10.1115/1.4004105. 
[55] Liu HC, Guo F, Guo L, Wong PL. A Dichromatic Interference Intensity Modulation Approach to Measurement of Lubricating Film Thickness. Tribol Lett 2015;58:1-11. doi:10.1007/s11249-015-0480$\mathrm{y}$.

[56] Dowson D, Toyoda A. A central film thickness formula in EHD line contacts. Proc 5th Leeds-Lyon Symp. Elastohydrodyn. Lubr. Relat. Top., London: MEP Press; 1978.

[57] Medina S, Fowell MT, Vlădescu S-C, Reddyhoff T, Pegg I, Olver a. V., et al. Transient effects in lubricated textured bearings. Proc Inst Mech Eng Part J J Eng Tribol 2015;0:1-15. doi:10.1177/1350650115572448.

[58] Hamrock BJ. Fundamentals of Fluid Film Lubrication. New York: McGraw Hill Inc; 1994.

[59] Johnson KL. Regimes of Elastohydrodynamic Lubrication. J Mech Eng Sci 1970;12:9-16. doi:10.1243/JMES_JOUR_1970_012_004_02.

[60] Taylor R. Squeeze film lubrication in piston rings and reciprocating contacts. Proc Inst Mech Eng Part J J Eng Tribol 2015;0:1-12. doi:10.1177/1350650114564234.

[61] Mishra PC, Rahnejat H, King PD. Tribology of the ring-bore conjunction subject to a mixed regime of lubrication. Proc Inst Mech Eng Part C J Mech Eng Sci 2009;223:987-98. doi:10.1243/09544062JMES1220. 